\title{
Ionospheric slab thickness - analysis, modelling and monitoring
}

\author{
S. M. Stankov ${ }^{*}$, R. Warnant \\ Royal Meteorological Institute (RMI), Ringlaan 3, B-1180 Brussels, Belgium \\ *Corresponding author. Tel.: +32 60395 472; Fax: +32 60395 423; E-mail: S.Stankov@ meteo.be
}

\begin{abstract}
A review of the climatological and storm-time behaviour of the ionospheric slab thickness is presented based on long-time observations at a European mid-latitude site, Dourbes $\left(50.1^{\circ} \mathrm{N}, 04.6^{\circ} \mathrm{E}\right)$, and on published results from other studies. An operational electron density and slab thickness monitoring system, established to provide real-time characterisation of the local ionospheric dynamics, is outlined together with some exemplary results.
\end{abstract}

Keywords: ionosphere, ionospheric storm, critical frequency, TEC, GNSS

\section{Introduction}

The ionospheric slab thickness $(\tau)$ is defined (Davies, 1990) as the ratio of the Total Electron Content (TEC) to the maximum ionospheric F2-layer electron density (NmF2), or in terms of the F2 critical frequency (foF2), $\tau=T E C /\left(1.24 \times 10^{-6}(f o F 2)^{2}\right)$, where TEC is measured in TEC units (1 $\mathrm{TECU}=10^{16}$ electrons per square metre), foF2 in $\mathrm{MHz}$, and $\tau$ in metres. In other words, $\tau$ represents the equivalent slab thickness/depth of an idealised ionosphere which has the same electron content as the actual ionosphere but uniform electron density equal to the maximum electron density (Fig.1). Strictly speaking, when TEC is obtained by means of GNSS (Global Navigation Satellite System) signals, the slab thickness value will contain a plasmaspheric component in addition to the 'pure' ionospheric component (Breed et al., 1997). Slab thickness measurements offer substantial information on the shape of the electron density profile, the neutral and ionospheric temperatures/gradients, on the ionospheric composition and dynamics (Titheridge, 1964; Amayenc et al., 1971; Titheridge, 1973; Fox et al., 1990; Davies and Liu, 1991).

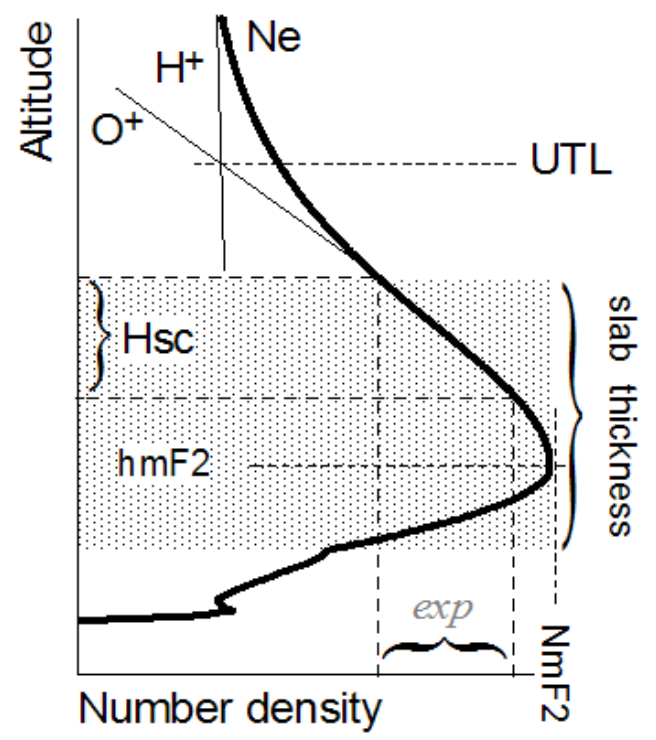

Fig.1. Schematic view of the vertical electron density profile with key characteristics such as the peak density (NmF2), peak height (hmF2), upper ion transition level (UTL), scale height (Hsc), and slab thickness $(\tau)$. 
Various studies indicated the close relationship between the ionospheric slab thickness and the vertical scale height (e.g. Wright, 1960; Furman and Prasad, 1973; Stankov and Jakowski, 2006). The plasma scale height is defined (Davies, 1990; Hargreaves, 1992) as $\mathrm{H}_{\mathrm{P}}=\mathrm{kT}_{\mathrm{P}} / \mathrm{m}_{\mathrm{i}} \mathrm{g}$, where $\mathrm{m}_{\mathrm{i}}$ is the ion mass, $T_{P}=T_{i}+T_{e}$ is the plasma temperature, $T_{i}$ and $T_{e}-$ ion and electron temperatures, $k-$ the Boltzmann constant $\left(1.380658 \times 10^{-23} \mathrm{~J} / \mathrm{deg}\right)$. Similarly, the scale height can be defined for each ion or neutral constituent (Van Zandt, 1967). Practically, the vertical scale height can be approximately deduced by measuring the vertical distance in which the concentration changes by a factor of an exponent (Fig.1).

Long-time observations have already proved that the slab thickness is subjected to substantial diurnal, annual, latitudinal and storm-time variations, and is influenced (albeit to a lesser extent) by solar and geomagnetic activity (Titheridge, 1973; Furman and Prasad, 1973; Kersley and HajebHosseinieh, 1976; Bhuyan and Tyagi, 1987; Davies and Liu, 1991; Buonsanto, 1999; Jayachandran et al., 2004). Although the $\tau$ irregular behaviour has been studied to some extent (e.g. Titheridge and Andrews, 1967; Kersley and Hajeb-Hosseinieh, 1976; Buonsanto et al., 1979; Fox et al., 1990; Jayachandran et al., 2004; Gulyaeva and Stanislawska, 2005), more investigations are needed in order to better understand and model short-term, day-to-day, and storm-time changes (Leitinger et al., 2004; Kouris et al., 2004).

This paper presents an overview of the climatological and storm-time behaviour of the slab thickness. In both cases, observations at a European mid-latitude site, Dourbes (coordinates: $50.1^{\circ} \mathrm{N}$, $4.6^{\circ} \mathrm{E}$ (geographic), $51.7^{\circ} \mathrm{N}, 88.9^{\circ} \mathrm{E}$ (magnetic)), will be used. Modelling and monitoring efforts are discussed and details of a local ionospheric electron density / slab thickness monitoring system will be presented together with results from recent interoperability test.

\section{Measurements}

The Royal Meteorological Institute (RMI) Geophysics Centre at Dourbes is a complex observational site where meteorological, ionosphere sounding, geomagnetic, TEC, and other measurements have been regularly carried out for many years. The Dourbes ionosonde (URSI code: DB049) carries out regular vertical incidence soundings with a Digisonde 256 developed by the University of Massachusetts - Lowell (Reinisch, 1996). Although the ionograms are automatically scaled, manually corrected hourly values of $f_{o} F_{2}$ are used here for more accurate results. TEC observations have been made with a GPS (Global Positioning System) receiver, collocated with the ionospheric sounder, applying a computational procedure based on the 'geometry-free' combination of the GPS code and phase measurements for resolving the ambiguities (Warnant, 1997, 1998; Warnant and Pottiaux, 2000). Receiver and satellite group delays are estimated by modelling the slant TEC with a simple polynomial depending on latitude and local time. The conversion to vertical TEC is performed by assuming the standard ionospheric thin-shell model at a mean ionospheric height of $350 \mathrm{~km}$ (e.g. Hofmann-Wellenhof et al., 2008). To obtain a TEC value representative of the ionosphere above a given location, selected and averaged are all values within a latitudinal range of $\pm 1.5^{\circ}$ over a 15 minute period. The slab thickness database consists of measurements since July 1994 , i.e. covering more than one complete solar cycle period. For the analysis, the data has been sorted according to season, solar and geomagnetic activity. Thus, measurements from July 1994 to December 1997 were selected to represent low solar activity (LSA) conditions and measurements from July 1999 to December 2002 for high solar activity (HSA). Also, 'low' magnetic activity (LMA) conditions are considered when $\mathrm{Kp}<3$, and active, 'high' magnetic activity (HMA) - when $\mathrm{Kp} \geq 3$. Three seasons (winter, equinox, and summer) have been defined as 91-day periods centred on the corresponding winter solstice (day of year, DoY, 356), summer solstice (DoY 173) and equinoxes (DoY 81 and DoY 264).

\section{Climatological behaviour}

Based on long-time series of foF2 and TEC data, numerous analyses have been published on the climatological behaviour of the slab thickness. As mentioned in Section 1, it has been found that the slab thickness shows diurnal, seasonal, spatial, solar and geomagnetic activity variations. Specific features were revealed, such as the pre-dawn enhancement (PDE) and the correlation with the plasma scale height behaviour. 
The mean diurnal variations of the slab thickness observed at Dourbes (Fig.2) are characterised with night-time values that are substantially higher than the day-time values during winter (night-today ratio between 1.40 at HSA and 1.55 at LSA), but higher day-time and lower night-time values during summer (night-to-day ratio of $0.80 \mathrm{HSA}$ to $0.86 \mathrm{LSA}$ ). A pre-dawn increase of the slab thickness is observed in the winter and equinox seasons, most pronounced during LSA winter between 05:00LT and 06:00LT, when average values exceed $400 \mathrm{~km}$. On average, the higher solar activity induces higher slab thickness values, both during night (up to $14 \%$ ) and day (up to $24 \%$ ). Active geomagnetic conditions also tend to elevate the slab thickness, more noticeably (in percentage terms) at HSA. Most prominent are the seasonal changes. During LSA, the average day-time values increase from $181 \mathrm{~km}$ in winter to $316 \mathrm{~km}$ in summer, while during HSA, the values almost double from winter $(205 \mathrm{~km})$ to summer $(390 \mathrm{~km})$. The night time values however, do not experience such large variability from winter to summer. There is comparatively small diurnal variation in $\tau$ during the equinoctial months.

The slab thickness exhibits a pronounced pre-dawn enhancement (PDE). The pre-dawn increase is a phenomenon closely related to the maintenance of the night-time F layer and can sufficiently well be explained (e.g. Davies and Liu, 1991) by the lowering of the ionospheric F layer immediately before sunrise to regions of greater neutral density, leading to increased ion loss due to recombination. The effect is believed to be particularly strong in the bottom-side ionosphere that includes the density peak. As a result, the decrease in $\mathrm{NmF} 2$ and the bottom-side density is much faster than the topside ionosphere where the loss rate is lower and thus, an enhancement occurs. In addition, plasmaspheric fluxes can also play a role in the increase. The magnitude of this increase is reportedly larger in low latitudes than in middle latitudes (Davies and Liu, 1991). By using data from Goose Bay $\left(53.32^{\circ} \mathrm{N}\right.$, $\left.299.16^{\circ} \mathrm{E}\right)$, Boulder $\left(40.00^{\circ} \mathrm{N}, 254.70^{\circ} \mathrm{E}\right)$, and Hawaii $\left(20.80^{\circ} \mathrm{N}, 203.50^{\circ} \mathrm{E}\right)$, Jayachandran et al. (2004) report that the PDE is a regular feature appearing during solar minimum in all seasons and latitudes, while during solar maximum it is still preserved for high and low latitudes but not evident at middle latitudes. Indeed, from our observations (Fig.2) the PDE seems to gradually disappear from winter to summer.

Substantial diurnal and seasonal variability of $\tau$ has been recorded during the years. Several studies in the northern hemisphere indicate that, generally, the slab thickness is greater in summer than in winter (Roger, 1964; Spalla and Ciraolo, 1994; Minakoshi and Nishimuta, 1994; Leitinger et al., 2004). Observations from the southern hemisphere confirm that the day-time slab thickness is greater in summer than in winter (Titheridge, 1973; Goodwin et al., 1995; Breed et al., 1997). Nevertheless, there are obviously some differences. For example, Jin et al. (2007) report that, in the East Asian zone, larger day-time values are maintained during equinox while smaller values are observed in summer and winter. Moreover, two peaks appear around 10:00 LT and 18:00 LT, most distinctively in summer.

Concerning the solar activity influence, Davies and Liu (1991) in a study based on measurements from globally distributed stations have found that the slab thickness varies linearly with the 12-month smoothed values of the $10.7-\mathrm{cm}$ solar radio flux. However, in middle latitudes they observed that, while the mid-day slab thickness increases in line with the solar flux during all seasons, the midnight slab thickness is essentially independent of the solar flux. It was also reported by Jayachandran et al. (2004) that, at higher latitudes, the slab thickness does not change significantly during low solar activity but, at higher solar activity, it increases in step with the increasing solar flux values. At lower latitudes, the mean daytime values remain more or less constant for both low and high solar activity. For the equatorial region, Klobuchar et al. (1991) calculated a slab thickness peak of about $510 \mathrm{~km}$ during solar maximum conditions and, during solar minimum conditions, a corresponding peak in the range of $460-560 \mathrm{~km}$ depending on the drift conditions. Also, at low and equatorial latitudes, the median day-time value of the slab thickness seems to be poorly correlated with the solar activity index $F_{10.7}$ (Chuo, 2007). In Australia, Breed et al. (1997) observed even a trend for increased slab thickness values at times of reduced solar influence. The PDE is reported to be well pronounced during the solar minimum, gradually disappearing during the ascending part of the solar cycle, and reappearing during the solar maximum, particularly in winter (Minakoshi and Nishimuta, 1994).

Although the magnetic activity does not appear to have significant influence on the $\tau$ variations at equatorial and low latitudes (Jayachandran et al., 2004; Chuo, 2007), active magnetic conditions seem to enhance the $\tau$ values at middle latitudes during solar minimum and at high latitudes during 
solar maximum (Buonsanto et al., 1979). A positive correlation has been detected between the monthly mean values of the slab thickness and the Ap geomagnetic index (Kersley and HajebHosseinieh, 1976), explained with the dependence of the neutral gas temperature on the level of magnetic disturbances. Fox et al. (1991) argue that while a correlation with daily magnetic indices can be expected, correlation with monthly mean magnetic activity is not justified.

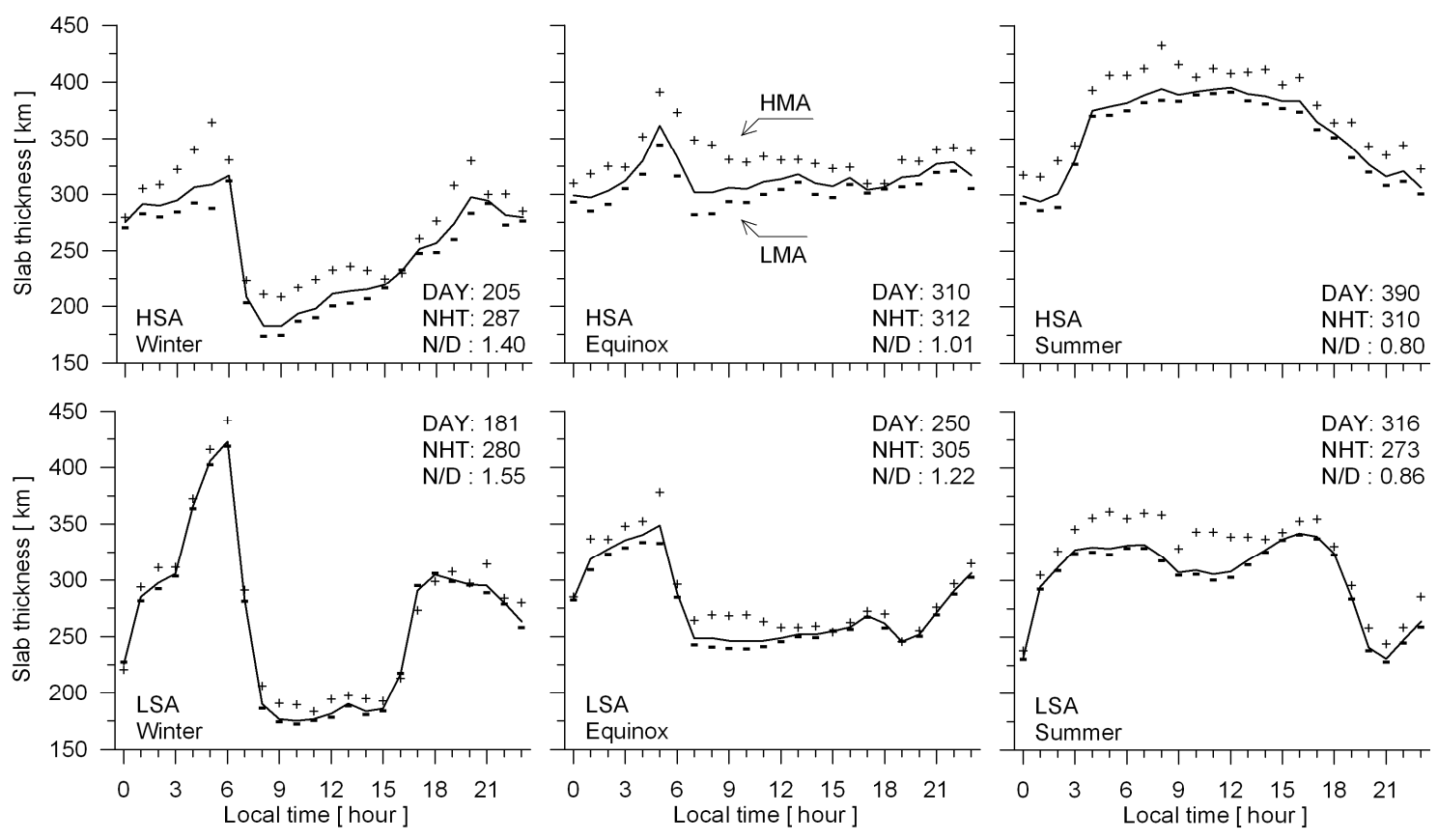

Fig.2. Diurnal variations of the slab thickness during low (bottom panels) and high (top panels) solar activity, as deduced from measurements at Dourbes $\left(50.1^{\circ} \mathrm{N}, 04.6^{\circ} \mathrm{E}\right)$. Solid lines show the average variations based on data from all geomagnetic conditions, the '-'symbols denote the average values observed during low magnetic activity (LMA, Kp<3) and the ' + ' symbols denote the values during high magnetic activity (HMA, $\mathrm{Kp} \geq 3$ ) conditions.
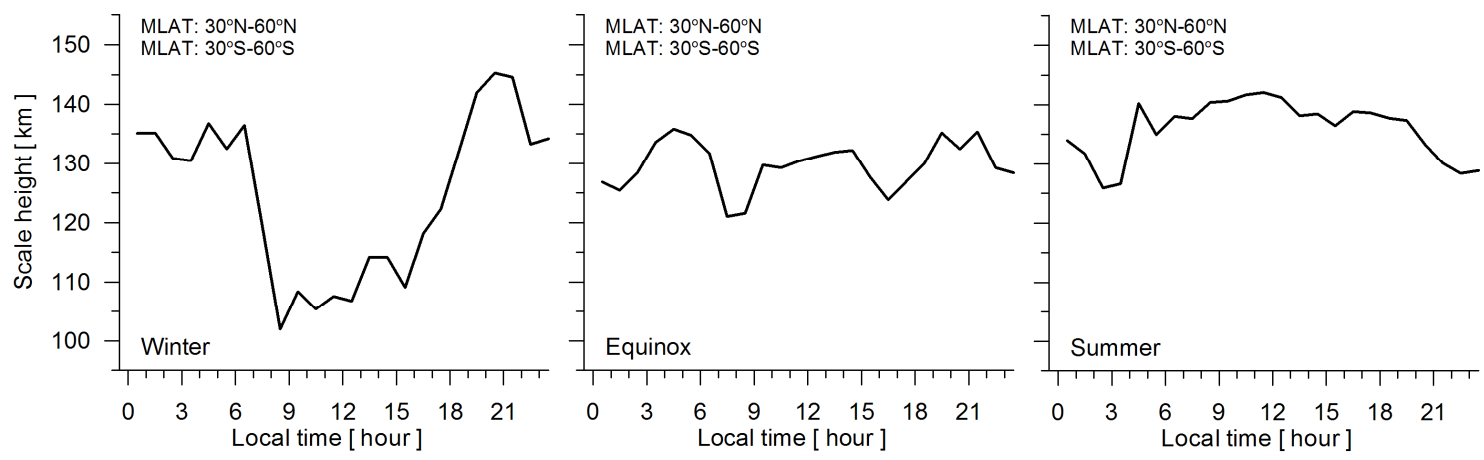

Fig.3. The topside ionospheric scale height, deduced from ionospheric occultation measurements (Stankov and Jakowski, 2006), middle geomagnetic latitudes (MLAT) during winter, equinox, and summer.

There are no clear-cut trends established in the spatial variations of the slab thickness. For example, Buonsanto et al. (1979) observed that the slab thickness is nearly always smaller at middle latitudes that at sub-auroral latitudes, while Klobuchar et al. (1991) found a region of enhanced slab thickness, extending from equatorial to dip latitudes of around $\pm 34^{\circ}$. Leitinger et al. (2004) conclude from theoretical considerations that there is an increase in the slab thickness towards the dip equator when the equatorial anomaly is on. Jayachandran et al. (2004) report (from northern hemispheric observations) that, during night, highest average values of $\tau$ (and night-to-day ratios) are recorded at high latitudes during solar maximum and at middle latitudes during solar minimum. Reported 
observations from the southern hemisphere do not indicate a noticeable latitudinal dependence in any season (Goodwin et al., 1995). By combining vertical electron content (derived by means of the Faraday effect on VHF signals from geostationary satellites) with peak electron density (derived from ionograms), and after neglecting solar activity, diurnal and seasonal variations, Leitinger et al. (2004) estimated that the overall mean slab thickness for Europe can be given as $230 \mathrm{~km}$ with a standard deviation of $50 \mathrm{~km}$. For high solar activity however, an increased average around $300 \mathrm{~km}$ is found to be more appropriate. The overall means for the American sector are slightly higher: $\tau=242 \mathrm{~km}$ for low solar activity, $\tau=267 \mathrm{~km}$ for moderate solar activity, and $\tau=292 \mathrm{~km}$ for high solar activity (Fox et al., 1991).

The average behaviours of the slab thickness and the topside ionospheric scale height seem to correlate well (cf. Fig.2 and Fig.3), due to the fact that most of the mechanisms determining the plasma scale height are valid for the slab thickness behaviour as well (Stankov et al., 2007). Here, the topside scale height value (at $\sim 425 \mathrm{~km}$ altitude) is obtained directly from the vertical electron density profile retrieved from ionospheric radio occultation measurements (Stankov and Jakowski, 2006). However, such correlation is not obvious under disturbed conditions when compression/expansion of the electron density profile is controlled mainly by dynamic forces such as neutral winds and electric fields.

\section{Storm-time behaviour}

The greatest variability in ionospheric slab thickness is observed during periods of geomagnetic storms. Here we present the slab thickness perturbations during two storms events, the summer storm of 15 July 2000 and the winter storm of 7 November 2004 (Fig.4).
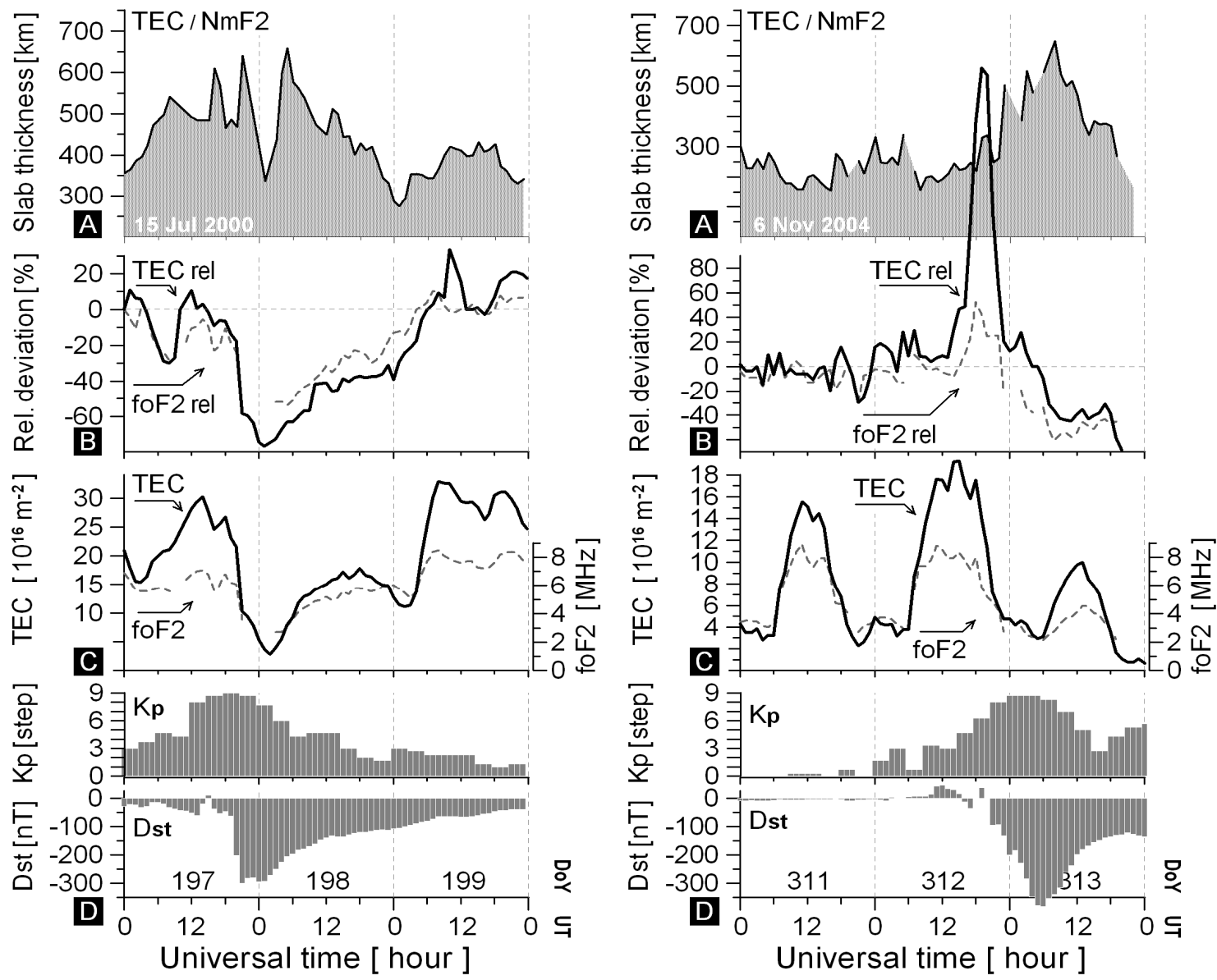

Fig.4. The slab thickness behaviour (top panels) during the geomagnetic storm periods of 15-17 July 2000 (left panels) and 6-8 November 2004 (right panels) as observed at Dourbes $\left(50.1^{\circ} \mathrm{N}, 04.6^{\circ} \mathrm{E}\right)$. 
The July 2000 storm was classified as a severe storm (Dst index fell to -300nT) which induced substantial negative response by both, foF 2 and TEC, most pronounced during the main and early recovery phases (from 14:35UT on 15 July 2000 until about 09:00UT on 16 July 2000) when the foF2 and TEC percentage deviations from monthly means dropped below $-50 \%$ and $-80 \%$, respectively (Fig.4, left panels). In fact, neither foF2 nor TEC experienced a 'positive' phase and were not able to recover to their normal values until 17 July. There is no foF2 data around 00:00UT on 16 July, so the slab thickness was not possible to calculate, but judging from the neighbouring values, it is obvious that the largest increase in the slab thickness occurred during the evening of 15 July and the early hours of 16 July when the slab thickness exceeded $600 \mathrm{~km}$. Increased slab thickness values were actually observed for most of the storm period.

The 7 November 2004 event was even more severe (Dst plunged to almost $-400 \mathrm{nT}$ ) and longer lasting. It was characterized by a pronounced positive response from both the foF 2 and TEC parameters during the onset phase of the storm, with percentage deviations from monthly means increasing above $50 \%$ for foF 2 and more than $200 \%$ for TEC (Fig.4, right panels). As a result, the slab thickness also increased substantially to peak at almost $650 \mathrm{~km}$ (in excess of $250 \%$ above the monthly means) during the early stages of the storm recovery phase when foF 2 was much more seriously depressed than TEC. The slab thickness remained higher than the monthly means until the evening hours of 8 November. In a previous study of the same storm with data from Juliusruh $\left(54.6^{\circ} \mathrm{N}, 13.4^{\circ} \mathrm{E}\right)$, a similar pattern of behaviour was observed (Stankov et al., 2005).

Key factors affecting the storm-time perturbations of the slab thickness are the levels of the solar and geomagnetic activity, the season, and the storm onset time, among others. In an extensive study, Fox et al. (1990) analyse in great detail the average storm patterns of the slab thickness behaviour by using a database of two solar cycles of TEC observations from Hamilton, MA $\left(42^{\circ} \mathrm{N}, 288^{\circ} \mathrm{E}\right)$ and ionosonde observations from Wallops Island, VA $\left(37.8^{\circ} \mathrm{N}, 284.5^{\circ} \mathrm{E}\right)$. The first noticeable feature is that the slab thickness is systematically enhanced during periods of geomagnetic disturbances, both during the positive and negative phases of TEC and NmF2. Although the duration of the average storm effect does not seem to be seasonally dependent, it appears that the enhancement on the first day of the storm is greater in winter, while that observed on the second day of the storm is greater in summer. The intensity of the storm proved important - the relative enhancements in $\tau$ are clearly greater during storms corresponding to greater peak Ap index values. While no dramatic trend is visible as a result of varying the level of solar activity, the effect on the slab thickness is greater during periods of higher solar activity. Significant differences in the $\tau$ storm patterns were detected with respect to the storm onset time. Thus, when onset occurs early in local time, a substantial increase is seen on the first day of the storm and a reduced effect on the second day. The enhancement tends to be greater for mid-day onsets and the effect lasts longer if the onset occurs later in the day.

Other researchers also noted that, if the sudden storm commencement occurs during daytime in winter, then a positive phase in the slab thickness is observed for the rest of the day followed by a negative phase the next day, whereas in summer, the slab thickness shows a positive phase during the entire storm period (Titheridge and Andrews, 1967; Mendillo, 1973). Prolonged slab thickness enhancements, lasting up to 48 hours after the storm onset, have been seen during the negative storm phases of NmF2 and TEC during solar maximum, while during solar minimum the enhancement may be significantly delayed (up to 24 hours after the storm onset) (Gulyaeva and Stanislawska, 2005). Theoretically, an increasing slab thickness (e.g. rising TEC accompanied by constant or decreasing foF2) indicates plasma uplifting - a manifestation of active electric fields that produce a vertical drift driving the plasma upwards to regions of lower ion loss (Buonsanto, 1999). At high / auroral latitudes, slab thickness increases may be attributed to heating processes leading to higher plasma temperatures, and additionally, at night, to the presence of an auroral E-layer (Buonsanto et al., 1979).

It is obvious that the reliable description and modelling of the day-to-day variations of the ionospheric slab thickness is a challenging task that should focus on long-term monitoring and analysing observations from many storm periods. 


\section{Modelling efforts}

In principle, the slab thickness values can be deduced from ionospheric models (empirical or otherwise) capable of providing vertical electron density profiles, so the focus was on improving the existing ionospheric models rather than developing a stand-alone model of the slab thickness on a global scale.

Nevertheless, there exists a number of local/regional models (e.g., Titheridge, 1973; HajebHosseinieh and Kersley, 1975; Huang, 1983; Fox et al., 1991; Davies and Liu, 1991; Spalla and Ciraolo, 1994). As summarised by Leitinger et al. (2004), these models provide a slab thickness value in the range between $170 \mathrm{~km}$ and $320 \mathrm{~km}$ for low solar activity and between 200 and $400 \mathrm{~km}$ for high solar activity, an increase in slab thickness with solar activity, and a slight positive dependence on geomagnetic activity for non-storm conditions. For strong magnetic storm conditions, only a slight day-time increase of 10 to $30 \mathrm{~km}$ is envisaged.

Fox et al. (1991) developed a mid-latitude model for the mean slab thickness values based on Fourier analysis applied to the Hamilton/Wallops Island database and compared the results with ionospheric models available at that time, including the International Reference Ionosphere (IRI). None of the models tested had values that were strong functions of latitude or longitude, so the comparisons were deemed equally valid for other mid-latitude locations. These comparisons yielded substantial discrepancies between the models' output and it was realised that more research relying on modern observation techniques is needed for successful modelling purposes.

A recent development, closely related to the slab thickness modelling efforts, is the global spacetime empirical model of the topside 'half-peak density height' (Gulyaeva, 2003; Gulyaeva and Titheridge, 2006). Similar to the sub-peak semi-thickness characteristic of the bottom-side electron density profile (Titheridge, 1973), the topside half-peak density height ( $\mathrm{h} 05_{\text {top }}$ ) is specified as the height in the topside ionosphere where the electron density is half the peak density NmF2 . In fact, this global empirical model provides the ratio $\mathrm{Rh} 05=\left(\mathrm{h} 05_{\text {top }}-\mathrm{hmF} 2\right) / \mathrm{hmF} 2$ of the topside half-width to the F-layer peak height, parameterised with respect to solar activity, local time, and geomagnetic latitude. The model database is constructed from topside sounding measurements carried out onboard the satellites ISIS1 (1969-1971, orbit altitude 500-3500 km), ISIS2 (1971-1980, altitude $1400 \mathrm{~km}$ ) and Interkosmos 19 (1979-1982, altitude 500-1000 km), thus covering more than one complete solar activity cycle, including the whole range of diurnal, seasonal, and spatial variations of the topside electron density profile.

\section{Monitoring developments}

An operational system for monitoring the local ionospheric density distribution has been established at the RMI Geophysics Centre at Dourbes (Jodogne and Stankov, 2002). The purpose of the LIEDR (Local Ionospheric Electron Density Reconstruction) system is to acquire and process data from simultaneous ground-based GNSS TEC and digital ionosonde measurements, and subsequently to deduce the local vertical electron density profile. LIEDR is primarily designed to operate in real time for service applications, and, if sufficient data from solar and geomagnetic observations are available, to provide short-term forecast as well. For research applications and further development of the system, a post-processing mode of operation is also envisaged.

A key module of the LIEDR system is the vertical electron density profile reconstruction that uses simultaneous digital ionosonde and GNSS measurements, together with empirically-obtained values of the $\mathrm{O}^{+} / \mathrm{H}^{+}$ion transition level. The ionosonde measurements are used primarily for obtaining the bottom-side profile, since digital ionosondes permit the reliable deduction of profiles from about $60 \mathrm{~km}$ up to $\mathrm{hmF}$. The topside electron density profile is deduced by employing a suitable ionospheric profiler (Chapman, Epstein, or Exponential) and solving a system of transcendental equations (resulting from the use of the above profilers) to obtain the unknown topside ion scale heights, sufficient to construct a unique electron density profile at the site of the measurements (Stankov and Muhtarov, 2001; Stankov, 2002; Stankov et al., 2003). Another key module of the LIEDR operational system is the real-time estimation of the ionospheric slab thickness.

To be able to provide forecast, additional information about the current solar and geomagnetic activity is needed. For the purpose, observations available in real time - at the Royal Institute of Meteorology (RMI), the Royal Observatory of Belgium (ROB), and the US National Oceanic and 
Atmospheric Administration (NOAA) - are used. Recently, a new hybrid model for estimating and predicting the local magnetic index $\mathrm{K}$ has been developed (Kutiev et al., 2009). This hybrid model has the advantage of using both, ground-based (geomagnetic field components) and space-based (solar wind parameters) measurements, which results in more reliable estimates of the level of geomagnetic activity - current and future.

LIEDR has been tested on actual measurements and is now operational with the nominal time resolution between two consecutive reconstructions set to 15 minutes. Short-term TEC and foF2 forecast is envisaged (Stankov et al., 2004) which will provide opportunity for slab thickness forecast as well.
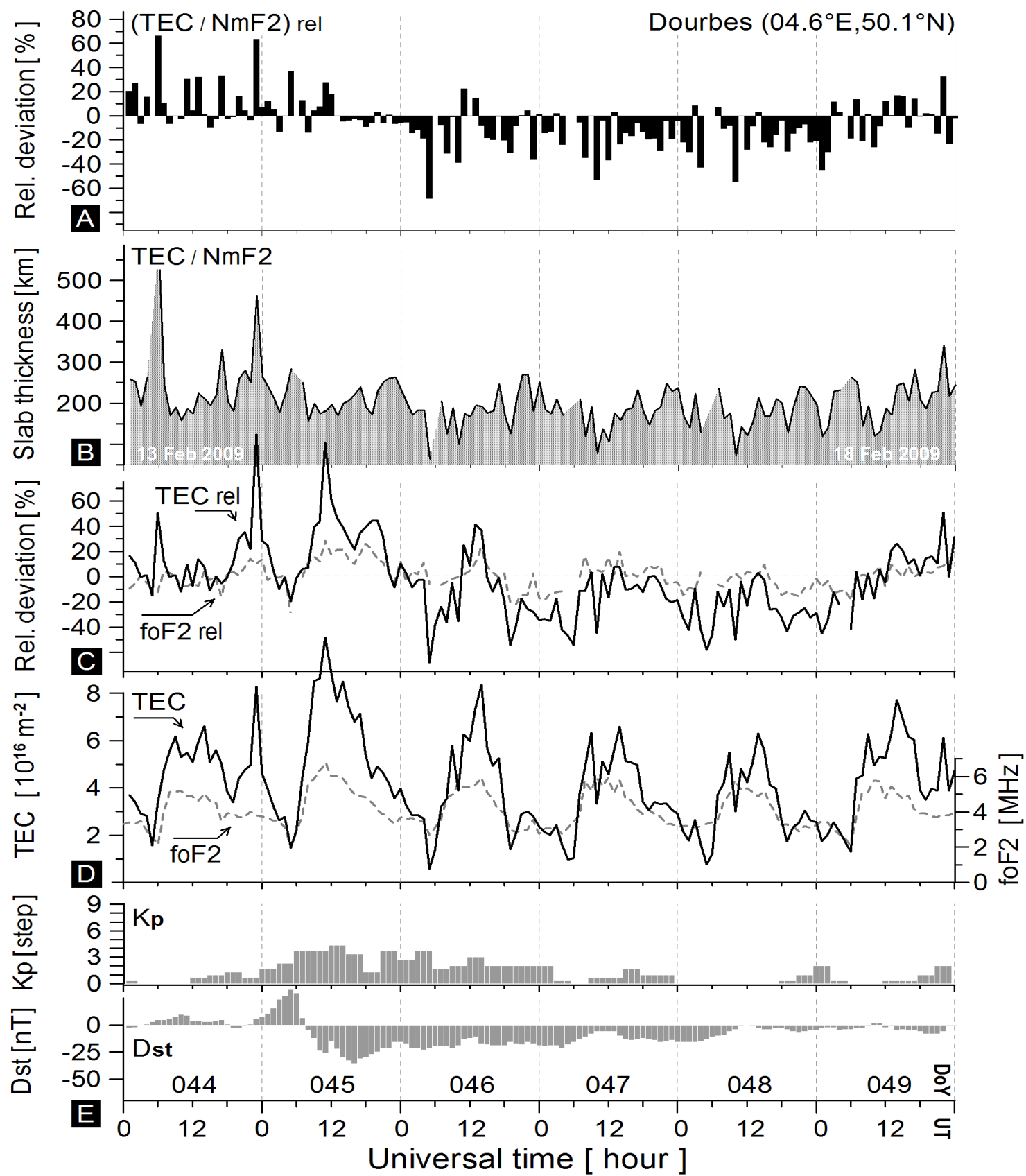

Fig.5. Ionospheric slab thickness monitoring/nowcast at Dourbes $\left(50.1^{\circ} \mathrm{N}, 04.6^{\circ} \mathrm{E}\right)$. Displayed are operational results of the slab thickness percentage deviation from the latest 27-day running means (A), the calculated slab thickness values (B), the TEC and foF2 percentage deviations from running means (C), the TEC and foF2 measurements (D), and the geomagnetic Kp and Dst indices (E). 
As an example, we present here the results of a LIEDR interoperability test during a recent minor storm event, from 13 February through 18 February 2009 (Fig.5). The figure shows the slab thickness values and their percentage deviations from the latest 27-day running means, together with the real time TEC and foF2 measurements. The focus is on monitoring the slab thickness percentage deviations (Fig.5A) as they provide a convenient summary of the current ionospheric situation (in the presented case, disturbed) by comparison with its regular state. It is clear that, in the here presented test results, the slab thickness behaviour is consistent with previously observed winter storm-time behaviour -- a positive phase during the storm onset period followed by a longer lasting negative phase. It should be noted that, due to the quicker TEC response to solar/magnetic forcing, the slab thickness increases well before the nominal start of the storm. Also, the slab thickness remains depressed for more than 72 hours during the ionosphere recovery phase. The ionosonde and TEC measurements were plotted in their raw form with the purpose of demonstrating the exact conditions encountered during the LIEDR system operation. Caution should be exercised when interpreting the operational slab thickness calculations, considering that the measurements may be quite noisy. In fact, the slab thickness combines the measurement errors of two ionospheric characteristics, which is further complicated by the physical differences in the measurements. While foF 2 is deduced from vertical incidence sounding, the TEC is measured along an oblique signal path, meaning that the two measurements may not necessarily refer to the same vertical electron density profile, particularly in times of large horizontal gradients.

\section{Conclusion}

The climatological and storm-time behaviour of the ionospheric slab thickness has been analysed based on measurements from a mid-latitude site (Dourbes) confirming the expected diurnal, seasonal, and geomagnetic activity dependence and also the close relationship with the topside ionospheric scale height. A brief review of observations made by other researchers has been presented as well. Although the majority of the published results are consistent with one another, several discrepancies (in either the observations or their interpretation) have been revealed, most notably on issues such as the level of dependence on solar and geomagnetic activity, location, etc. There is also insufficient understanding of the day-to-day and storm-time variability.

The ionospheric monitoring capabilities of the slab thickness remain largely unexplored, despite the fact that, operationally, it is a very useful parameter as it allows a simple conversion between foF 2 and TEC and additionally, it closely relates to other important ionospheric characteristics. From this aspect, various possibilities exist for utilizing the ionospheric slab thickness modelling/monitoring efforts.

For example, if having instantaneous access to data from regional/global digital ionosonde and GNSS reference networks, it would be possible to provide regional/global monitoring of the slab thickness in real time. This is achievable, considering that various space weather related services have already been established (e.g. in Europe: Jakowski et al., 2005; Belehaki et al., 2006; Crespon et al., 2008).

If available in real time, over a region of interest, the operational slab thickness monitoring can be used for characterizing and eventually predicting the ionospheric density distribution/gradients, the extent of ionospheric density anomalies and their propagation characteristics (e.g. Stankov et al., 2005). From this aspect, it is believed that the permanent ionospheric monitoring (incl. slab thickness) can assist various GNSS applications, such as improving the integrity and performance of network RTK positioning services, the 'ionospheric threat' identification/estimation in aircraft navigation, etc. (Stankov and Jakowski, 2006, 2007; Pullen et al., 2008; Stankov et al., 2009).

\section{Acknowledgements}

The authors thank K. Stegen, G. Crabbe, E. Van Malderen, and L. Lejeune for the past and ongoing technical support. This work is funded by the Royal Meteorological Institute (RMI) of Belgium via grant GJU/06/2423/CTR/GALOCAD and the RMI Solar-Terrestrial Centre of Excellence (STCE). 


\section{References}

Amayenc, P., Bertin, F., Papet-Lepine, J., 1971. An empirical relationship between ionospheric equivalent slab thickness and mean gradient of the electron temperature in the F-region. Planetary and Space Science, 19(10), 1313-1317.

Belehaki, A., Cander, L., Zolesi, B., Bremer, J., Juren, C., Stanislawska, I., Dialetis, D., Hatzopoulos, M., 2006. Monitoring and forecasting the ionosphere over Europe: The DIAS project. Space Weather, 4, S12002, doi:10.1029/2006SW000270.

Breed, A. M., Goodwin, G.L., Vandenberg, A.M., Essex, E.A., Lynn, K.J.W., Silby, J.H., 1997. Ionospheric total electron content and slab thickness determined in Australia. Radio Science, 32(4), 1635-1643.

Buonsanto, M.J., 1999. Ionospheric storms - a review. Space Science Reviews, 88, 563-601.

Buonsanto, M.J., Mendillo, M., Klobuchar, J.A., 1979. The ionosphere at $\mathrm{L}=4$ : average behaviour and the response to geomagnetic storms. Annales Geophysicae, 35(1), 15-26.

Bhuyan, P. K., Tyagi, T.R., 1987. Lunar and solar daily variations of equivalent slab thickness at Delhi. Geophysical Journal International, 88(2), 487.

Chuo, Y.J., 2007. The variation of ionospheric slab thickness over equatorial ionization area crest region. Journal of Atmospheric and Terrestrial Physics, 69(8), 947-954.

Crespon, F., Jeansou, J., Helbert, J., Moreaux, G., Lognonne, P., Garcia, R., 2008. SPECTRE: a web Service for Ionospheric Products. in: Proc. $5^{\text {th }}$ European Space Weather Week, November 2008, Brussels.

Davies, K., 1990. Ionospheric Radio. Peter Peregrinus Ltd., London.

Davies, K., Liu, X.M., 1991. Ionospheric slab thickness in middle and low-latitudes. Radio Science, 26(4), 997-1005.

Fox, M.W., Mendillo, M., Spalla, P., 1990. The variation of ionospheric slab thickness during geomagnetic storms. in: Proc. Intl. Beacon Sat. Simposium (IBSS), June 1990, Tucuman, Argentina.

Fox, M.W., Mendillo, M., Klobuchar, J.A., 1991. Ionospheric equivalent slab thickness and its modeling applications. Radio Science, 26, 429-438.

Furman, D.R., Prasad, S.S., 1973. Ionospheric slab thickness: its relation to temperature and dynamics. Journal of Geophysical Research, 78(25), 5837-5843.

Goodwin, G.L., Silby, J.H., Lynn, K.J.W., Breed, A.M., Essex, E.A., 1995. GPS satellite measurements: ionospheric slab thickness and total electron content. Journal of Atmospheric and Terrestrial Physics, 57, 1723-1732.

Gulyaeva, T.L., 2003. Variations of the half-width of the topside ionosphere according to the observations by space ionosondes ISIS 1, ISIS 2, and IK 19. Geomagnetism and Aeronomy, 4(3), 201-207.

Gulyaeva, T., Stanislawska, I., 2005. Night-day imprints of ionospheric slab thickness during geomagnetic storm. Journal of Atmospheric and Solar-Terrestrial Physics, 67(14), 1307-1314.

Gulyaeva, T.L, Titheridge, J.E., 2006. Advanced specification of electron density and temperature in the IRI ionosphere-plasmasphere model. Advances in Space Research, 38(11), 2587-2595.

Hajeb-Hosseinieh, H., Kersley, L., 1975. Analysis of satellite recordings. in: Studies of ionospheric slab thickness. Interim scientific report (Air Force Cambridge Research Laboratory, Bedford, MA), TR-75-0521, 55 pages.

Hargreaves, J.K., 1992. The solar-terrestrial environment, Cambridge University Press, Cambridge.

Hofmann-Wellenhof, B., Lichtenegger, H., Wasle E., 2008. GNSS-Global Navigation Satellite Systems: GPS, GLONASS \& more, Springer, Vienna New York, 516 pages.

Huang, Y.N., 1983. Some results of ionospheric slab thickness observations at Lunping. Journal of Geophysical Research, 88(A7), 5517-5522.

Jakowski, N., Stankov, S.M., Klaehn, D., 2005. Operational space weather service for GNSS precise positioning. Annales Geophysicae, 23(9), 3071-3079.

Jayachandran, B., Krishnankutty, T.N., Gulyaeva, T.L., 2004. Climatology of ionospheric slab thickness. Annales Geophysicae, 22(1), 25-33.

Jin, S.G., Cho, J.H., Park, J.U., 2007. Ionospheric slab thickness and its seasonal variations observed by GPS. Journal of Atmospheric and Solar-Terrestrial Physics, 69(15), 1864-1870. 
Jodogne, J.C., Stankov, S.M., 2002. Ionosphere-plasmasphere response to geomagnetic storms studied with the RMI-Dourbes comprehensive database. Annals of Geophysics, 45(5), 629-647.

Kersley, L., Hajeb-Hosseinieh, H., 1976. The dependence of ionospheric slab thickness on geomagnetic activity. Journal of Atmospheric and Terrestrial Physics, 38(9-10), 1357-1360.

Klobuchar, J.A., Anderson, D.N., Doherty, P.H., 1991. Model studies of the latitudinal extent of the equatorial anomaly during equinoctial conditions. Radio Science, 26(4), 1025-1047.

Kouris, S.S., Xenos, T.D., Polimeris, K.V., Stergiou, D., 2004. TEC and foF2 variations: preliminary results. Annales Geophysicae, 47(4), 1325-1332.

Kutiev, I., Muhtarov, P., Andonov, B., Warnant, R., 2009. Hybrid model for nowcasting and forecasting the $\mathrm{K}$ index. Journal of Atmospheric and Solar-Terrestrial Physics, 71(5), 589-596.

Leitinger, L., Ciraolo, L., Kersley, L., Kouris, S.S., Spalla, P., 2004. Relations between electron content and peak density - regular and extreme behaviour. Annals of Geophysics, 47(2/3), 10931107.

Mendillo, M., 1973. A study of the relationship between geomagnetic storms and ionospheric disturbances at mid latitudes. Planetary and Space Science, 21, 349-358.

Minakoshi, H., Nishimuta, I., 1994. Ionospheric electron content and equivalent slab thickness at lower mid-latitudes in the Japanese zone. in: Proc. International Beacon Satellite Symposium (IBSS), University of Wales, U.K., p.144.

Pullen, S., Park, Y.S., Enge, P., 2008. The Impact and Mitigation of Ionosphere Anomalies on Ground-Based Augmentation of GNSS. in: Proc. Ionospheric Effects Symposium (IES), May 1315, 2008, Alexandria, VA, USA, Paper No. A076.

Reinisch, B.W., 1996. Modern Ionosondes. in: Kohl, H., Rüster, R., and Schlegel, K. (Eds.) Modern Ionospheric Science. European Geophysical Society, Katlenburg-Lindau, Germany, 440-458.

Roger, R.S., 1964. Measurements of the equivalent slab thickness of the daytime ionosphere. Journal of Atmospheric and Terrestrial Physics, 26(4), 475-497.

Spalla, P., Ciraolo, L., 1994. TEC and foF2 comparison. Annali di Geofisica, 37(5), 929-938.

Stankov, S.M., Muhtarov, P.Y., 2001. Reconstruction of the electron density profile from the total electron content using upper transition level and vertical incidence sounding measurements. Comptes Rendus de l'Academie Bulgare des Sciences, 54(9), 45-48.

Stankov, S.M., 2002. Evaluation of analytical ionospheric models used in electron density profile reconstruction. Acta Geodaetica et Geophysica Hungarica, 37(4), 385-401.

Stankov, S.M., Jakowski, N., Heise, S., Muhtarov, P., Kutiev, I., Warnant, R., 2003. A new method for reconstruction of the vertical electron density distribution in the upper ionosphere and plasmasphere. Journal of Geophysical Research, 108(A5), 1164, doi:10.1029/2002JA009570.

Stankov, S.M., Kutiev, I.S., Jakowski, N., Wehrenpfennig, A., 2004. GPS TEC forecasting based on auto-correlation analysis. Acta Geodaetica et Geophysica Hung., 39(1), 1-14.

Stankov, S.M., Jakowski, N., Wilken, V., Tsybulya, K., 2005. Generation and propagation of ionospheric disturbances studied by ground and space based GPS techniques. Proc. Ionospheric Effects Symposium (IES), May 3-5, 2005, Alexandria, VA, USA, Paper No. A064/9B2, 807814.

Stankov, S.M., Jakowski, N., 2006. Topside ionospheric scale height analysis and modelling based on radio occultation measurements. Journal of Atmospheric and Solar-Terrestrial Physics, 68(2), 134-162.

Stankov, S.M., Jakowski, N., 2007. Ionospheric effects on GNSS reference network integrity. Journal of Atmospheric and Solar-Terrestrial Physics, 69(4-5), 485-499.

Stankov, S.M., Marinov, P., Kutiev, I., 2007. Comparison of NeQuick, PIM, and TSM model results for the plasma scale and transition heights. Advances in Space Research, 39(5), 767-773.

Stankov, S.M., Warnant, R., Stegen, K., 2009. Trans-ionospheric GPS signal delay gradients observed over mid-latitude Europe during the geomagnetic storms of October-November 2003. Advances in Space Research, 43(9), 1314-1324.

Titheridge, J.E., 1964. The refraction of satellite signals - II. Experimental results. Journal of Atmospheric and Terrestrial Physics, 26(2), 177-191.

Titheridge, J.E., 1973. The slab thickness of the mid-latitude ionosphere. Planetary and Space Science, 21, 1775-1793. 
Titheridge, J.E., Andrews, M.K., 1967. Changes in the topside ionosphere during a large geomagnetic storm. Planetary and Space Science, 15, 1157-1167.

Van Zandt, T.E., 1967. The neutral atmosphere and the quiet ionosphere. In: Matsushita, S., and Campbell, W.H. (eds.), Physics of the geomagnetic phenomena. Academic Press, NewYork, 505559.

Warnant, R., 1997. Reliability of the TEC computed using GPS measurements - the problem of hardware biases. Acta Geodaetica et Geophysica Hungarica, 32(3-4), 451-459.

Warnant, R., 1998. Detection of irregularities in the total electron content using GPS measurements application to a mid-latitude station. Acta Geodaetica et Geophysica Hungarica, 33(1), 121-128.

Warnant, R., Pottiaux, E., 2000. The increase of the ionospheric activity as measured by GPS. Earth Planets and Space, 52(11), 1055-1060.

Wright, J.W., 1960. A model of the F-region above hmaxF2. Journal of Geophysical Research, 65(1), 185-191. 